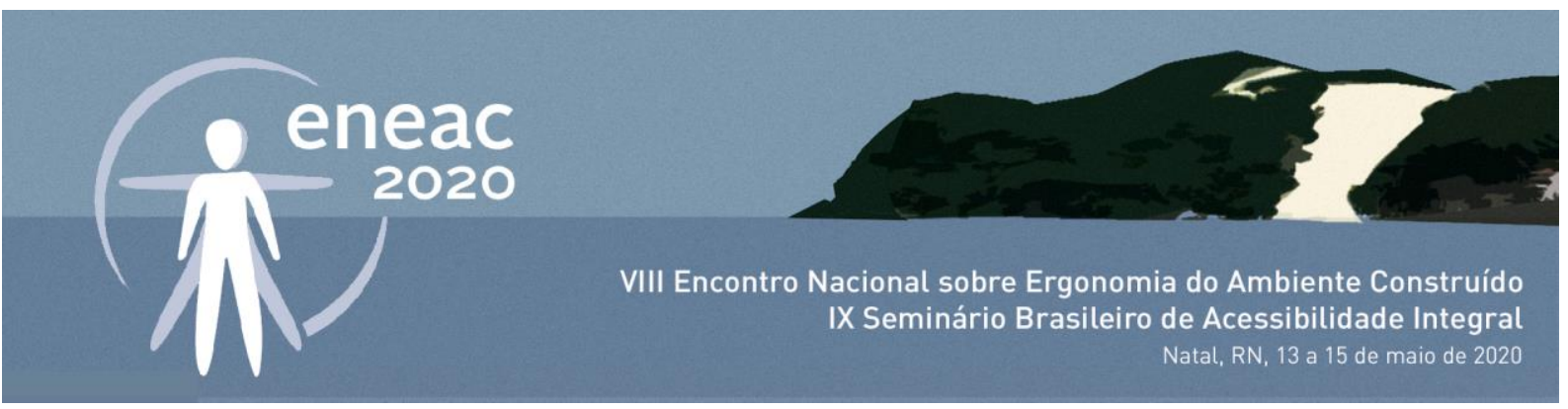

\title{
Avaliação ergonômica do ambiente construído em uma Instituição de Longa Permanência para Idosos (ILPI)
}

\author{
Ergonomic evaluation of the environment built in a Long Term \\ Care Institution for the Elderly (LTCI)
}

KAROLINE LIMA NASCIMENTO

Arquiteta e Urbanista, Mestranda em Desenvolvimento Urbano, UFPE, karoline.tg.ufpe@gmail.com

LAYSA CIBELLE ALVES MONTEIRO

Arquiteta e Urbanista, Mestranda em Desenvolvimento Urbano, UFPE, laysacamonteiro@gmail.com

\section{RESUMO}

O aumento da expectativa de vida e o envelhecimento da população são realidades observadas na sociedade atual, bem como o notável aumento da população idosa, tanto nos países desenvolvidos quanto nos em desenvolvimento, principalmente daqui a 50 anos. Esse aumento traz consequências sociais e econômicas diretas, além da velhice impor um novo ritmo de vida que exige maior dedicação e cuidados por parte da família. Quando isso não é possível, existe a opção da mudança do idoso para uma Instituição de Longa Permanência para Idosos (ILPI). Diante de tais considerações e levando em conta as complicações que o envelhecimento traz à realização das tarefas simples do dia a dia é importante discutir as diretrizes projetuais desses ambientes. Nesse contexto, este artigo apresenta uma aplicação da metodologia de Análise Ergonômica do Ambiente Construído em uma ILPI localizada na cidade de João Pessoa - PB. A ergonomia é o estudo científico interdisciplinar do ser humano e da sua relação com o ambiente de trabalho, é de importante atuação nas mais diversas atividades, melhorando a produtividade e o conforto físico e psicológico dos seus usuários. Com o objetivo de avaliar a forma como as pessoas interagem com o ambiente, visou-se identificar o nível de satisfação de seus usuários e observar condicionantes passíveis de estudo para futuras intervenções na edificação em estudo.

PALAVRAS-CHAVE: ILPI, análise ergonômica do ambiente, ambiente construído. 


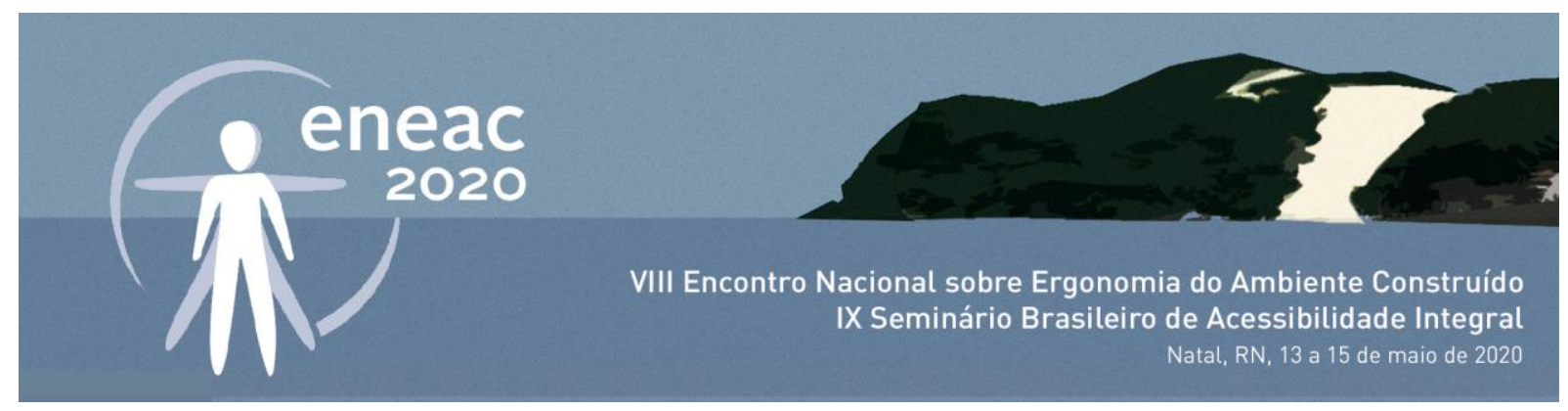

\begin{abstract}
The increase in life expectancy and the aging of the population are realities observed in today's society, as well as the notable increase in the elderly population, both in developed and developing countries, especially in 50 years from now. This increase has direct social and economic consequences, in addition to old-age imposing a new pace of life that requires greater dedication and care by the family. When this is not possible, there is the option of moving the elderly to a Long Term Care Institution for the Elderly (LTCI). Given these considerations and taking into account the complications that aging brings to the performance of simple daily tasks, it is important to discuss the design guidelines of these environments. In this context, this article presents an application of the Ergonomic Analysis of the Built Environment methodology at an LTCl located in the city of João Pessoa - PB. Ergonomics is the interdisciplinary scientific study of the human being and his relationship with the work environment, it is important in various activities, improving the productivity and the physical and psychological comfort of its users. In order to assess the way people interact with the environment, the aim was to identify the level of satisfaction of its users and observe conditions that could be studied for future interventions in the studied building.
\end{abstract}

KEYWORDS: LTCI, Ergonomic evaluation of the environment, environment built

\title{
1 INTRODUÇÃO
}

Segundo a Organização Mundial de Saúde (OMS), idoso é considerado a pessoa com mais de 65 anos de idade. De acordo com a Constituição Federal de 1988, pela Política Nacional do Idoso de 1994 e pelo Estatuto do Idoso de 2003, é dever da família o cuidado do idoso, uma vez que é seu principal responsável. Entretanto, a velhice impõe um novo ritmo de vida que exige uma maior dedicação e cuidados por parte da família, o que muitas vezes implica no abandono da atividade profissional por parentes, em idade ativa, ou a contratação de um cuidador de idosos, que geralmente tem um custo alto. Por isso, "o estado é um agente de protagonismo imprescindível na determinação de políticas oficiais destinadas ao atendimento geral da ancianidade" (FRANK, 2016, p: 6), principalmente, porque a carência de renda e a impossibilidade de atenção integral são consideradas alguns dos principais motivos que levam a família a optar pela institucionalização.

É importante ressaltar que o termo institucionalização difere de termos como 'internação' ou 'reclusão' e deve ser entendido no sentido de que qualquer modalidade de moradias para idosos, como casa lar, moradia tutelar, entre outras, se enquadra através do termo cunhado pela Sociedade Brasileira de Geriatria e Gerontologiai como uma ILPI (Instituição de Longa Permanência para Idosos), termo também adotado pela OMS e, como uma alternativa de moradia, não resultado de abandono ou de uma modalidade de habitação puramente assistencialista. Diferente do que muitos pensam as Instituições de Longa Permanência para Idosos não funcionam como clinicas médicas ou terapêuticas. Há, em todas ILPIs, um acompanhamento continuo auxiliando os idosos em seus tratamentos médicos e algumas oferecem o suporte no deslocamento caso o paciente precise se deslocar para uma consulta.

Faz-se necessário destacar os estudos realizados no campo da geriatria onde mostram o crescente aumento do envelhecimento da população e a necessidade de políticas públicas que visem ao planejamento de instituições públicas para idosos. Como todo cidadão, o idoso tem direito a qualidade de vida e ao bem-estar, e dentro desses dois pontos está inclusa a acessibilidade urbana e 


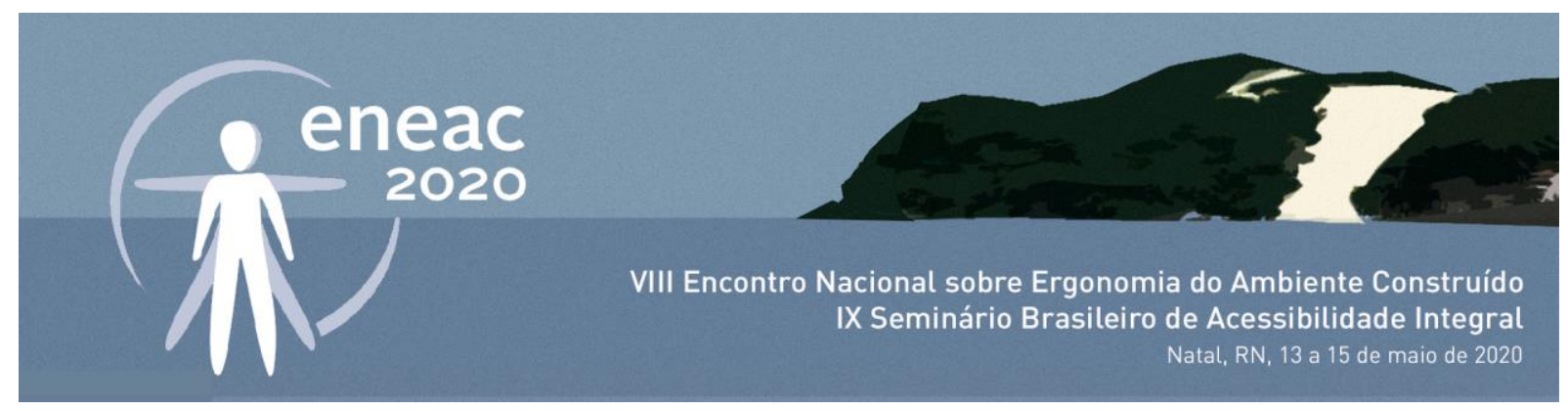

arquitetônica. A adaptação dos ambientes de longa permanência para idosos é de suma importância para o fim de barreiras que atrapalhem no deslocamento e, ou machuquem o usuário.

No Brasil, a quantidade de residências para atender à ancianidade é baixa, e quando comparada aos dados demográficos dessa população, atende a um número muito pequeno de idosos. De acordo com dados do Instituto de Pesquisa Econômica Aplicada (IPEA) publicados em 2011, havia um total de 83 mil idosos em abrigos públicos e privados, mas, já em 2018, Ana Amélia Camaranoii, afirma que esse número já estava em cerca de 100 mil idosos.

Segundo a Agência Nacional de Vigilância Sanitária, a Anvisa, que está regulamentando os serviços de uma ILPI desde 2005, é necessário cautela na escolha de uma moradia como essa para quem vai usála. É fundamental verificar se o local é regulamentado conforme as leis; observar se as instalações possuem áreas em que o idoso possa se machucar; buscar um local que ofereça uma alimentação regularizada, bons cuidadores e horários livres para o recebimento de visitas.

\section{OBJETIVO}

O objetivo desta pesquisa foi desenvolver uma avaliação metodológica de um dos blocos que compõe uma ILPI localizada da cidade de João Pessoa - PB, no bairro dos Estados, a fim de diagnosticar sua relação com os usuários numa escala física e psicológica, fazendo uso dos conceitos da Ergonomia e abordagens interdisciplinares para avaliar também sua acessibilidade, layout e mobiliários, conforto ambiental e etc. Além disso, é possível avaliar também de que forma o espaço físico das ILPIs interfere no bem-estar dos idosos e que influência possuem na sua qualidade de vida, direcionando de forma mais clara e concisa as diretrizes das intervenções.

\section{METODOLOGIA}

A análise foi feita a partir da Metodologia Ergonômica do Ambiente Construído, proposta por Villarouco (2008). Foi escolhida tal metodologia por se conseguir resultados levando em consideração os pontos de vista dos principais atores envolvidos: o pesquisador, como avaliador técnico, o usuário, que recebe a influência direta do ambiente, e os funcionários e gestores, que além de receberem a interferência do ambiente para a realização das atividades cotidianas, também conseguem detectar as satisfações e as insatisfações dos usuários.

Com a finalidade de avaliação metodológica de um ambiente e sua relação com os usuários, numa escala física e psicológica, de acordo com suas necessidades e características atuais, na tentativa de propor também melhorias que superassem algumas deficiências provenientes da etapa projetual, caso houvesse. A Ergonomia considera que os ambientes de trabalho estejam adaptados ao homem, consequentemente, as metodologias utilizadas se aproximam do usuário quanto à avaliação de suas satisfações e insatisfações.

Ao cruzar os dados obtidos em visitas de campo com os aspectos sociais, psicológicos e culturais, é possível se aprofundar nas problemáticas e nas potencialidades do ambiente em estudo, para chegar a alternativas de minimização ou eliminação dos problemas detectados (VILLAROUCO, 2002). 


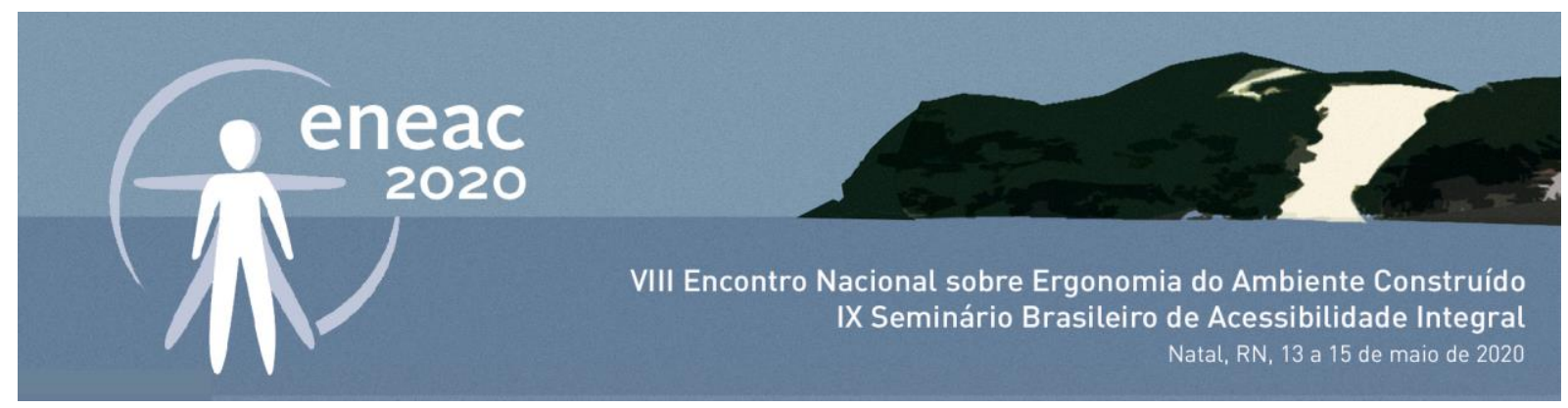

A avaliação do ambiente construído realizado foi desenvolvida levando em consideração as normas técnicas, o Código de Obras de João Pessoa e sua relação com as reais necessidades dos usuários dos ambientes das instituições. A análise realizada foi de fundamental importância, pois com ela foi possível detectar a influência dos fatores espaciais, ambientais e organizacionais, que influenciam de forma direta no desenvolvimento das atividades e na sensação de bem-estar dos idosos e funcionários da ILPI.

Abrangendo as etapas que permeiam a percepção inicial que se tem de um ambiente, medições de temperatura, ruído e iluminância do ambiente físicos e variantes do conforto ambiental, a metodologia escolhida tem como ponto inicial a chamada Análise Ergonômica do Trabalho (AET). Dotado de interações que podem ser favoráveis ou não à produtividade do trabalho realizado, os ambientes das instituições foram analisados a partir de cinco etapas:

- Análise Global do Ambiente - para entender a configuração espacial e os processos de trabalho, através da técnica da observação sistemática. Foi elaborado um checklist com os aspectos que seriam observados.

- Identificação da Configuração Ambiental - levantamentos de dados físicos, dimensões de mobiliários, medições térmicas, acústicas e lumínicas, entre outros, através da técnica da observação sistemática;

- Avaliação do Ambiente em Uso - através da técnica da observação sistemática diante das atividades realizadas para entender se o ambiente é um facilitador ou um obstáculo para a realização dessas atividades;

- Análise da Percepção do Usuário - através de formulário de opinião dos usuários e questionários aplicados com funcionários, sobre o ambiente para entender como os mesmos se relacionam com o espaço;

- Diagnóstico Ergonômico do Ambiente - que consiste na avaliação técnica em concordância com os dados subjetivos obtidos pelos questionários e formulários aplicados e com os dados obtidos a partir de medições.

\section{A INSTITUIÇÃO}

A ILPI escolhida como objeto foi fundada há 106 anos e foi criada com o propósito de ser um lar de acolhimento de idosos, sendo chamado anteriormente de Asilo da Medicidade. Hoje, atende 90 idosos, sendo 75 mulheres e 15 homens. Está localizada no Bairro dos Estados, e os idosos são divididos em blocos por níveis de dependênciaiii, sendo um bloco específico para os idosos que possuem algum tipo de demência como o Mal de Alzheimer.

É uma instituição filantrópica, que tem como renda além de doações, $20 \%$ dos idosos que recebem um salário mínimo e $70 \%$ que pagam pelo valor de acordo com o tipo do bloco que residem. É mantida pela ANBEAS, a Associação Norte Brasileira de Educação e assistência social, formada por uma congregação de freiras com o propósito de atender as pessoas em situação de vulnerabilidade social, como idosos, crianças e famílias de baixa renda. 


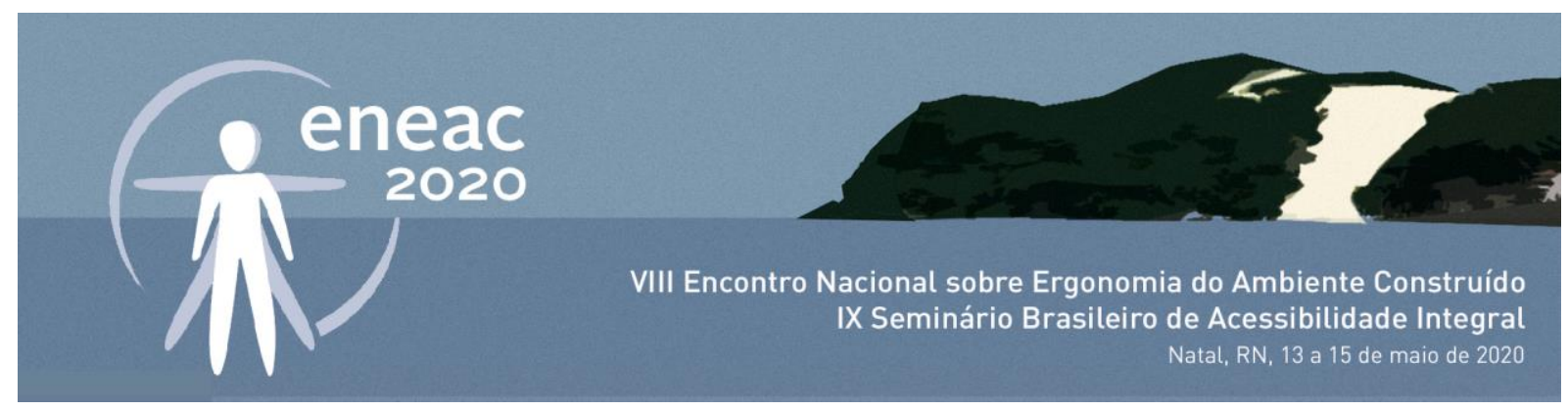

A edificação está localizada na Av. Santa Catarina, uma avenida de grande fluxo de veículos, principalmente de transporte público (figura 1). A edificação é reconhecida pelo seu nome pintado em toda a extensão do muro da fachada voltada para a avenida, bem como presente na portaria. Conforme exigido pela RDC 283/2005 da Anvisa, a edificação possui duas portas de acesso, a entrada principal pela Av. Santa Catarina, e uma entrada de serviços pela Av. São Paulo.

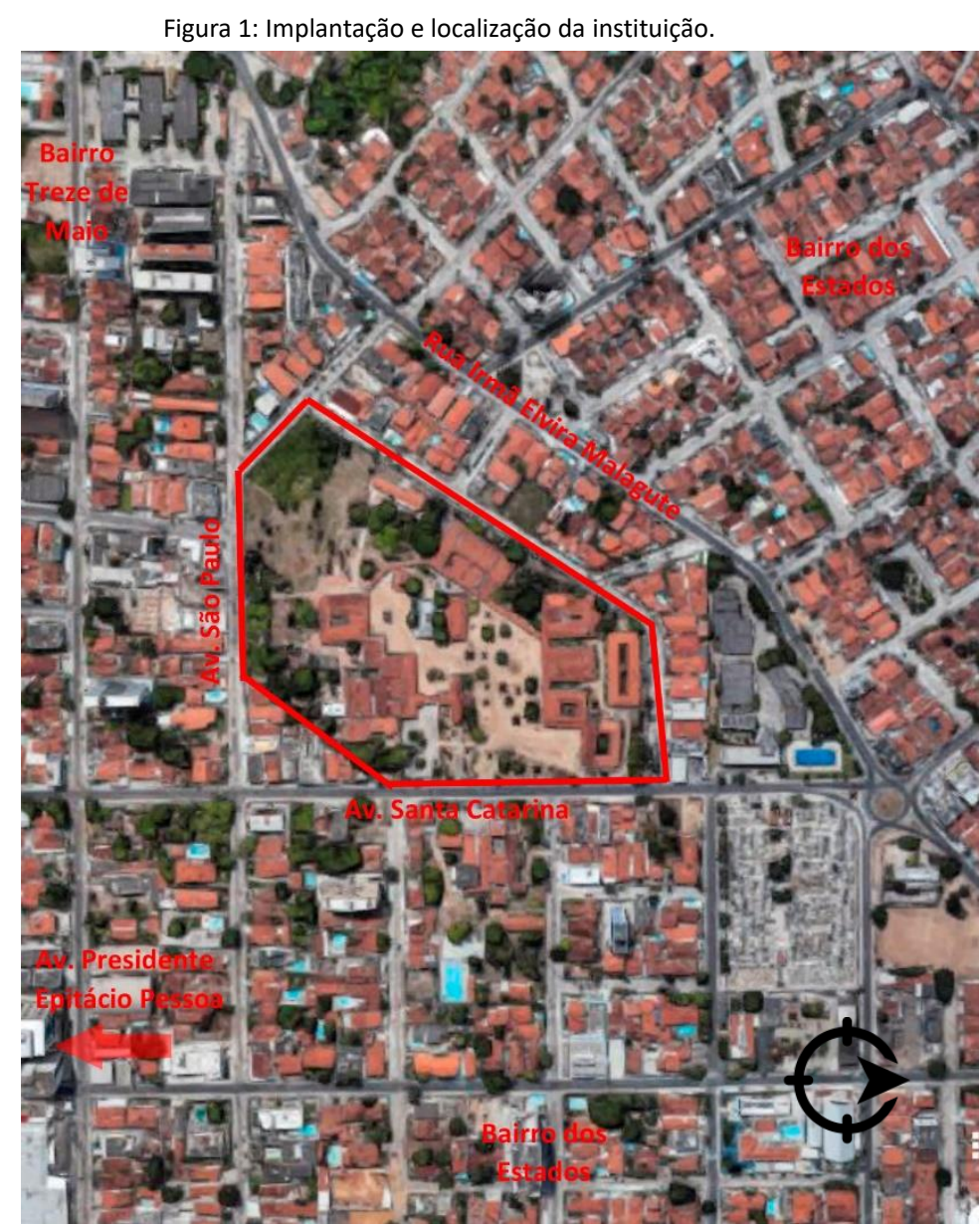

Fonte: Adaptado do Google Maps, 2017.

A instituição ocupa uma área de $52.751,30 \mathrm{~m}^{2}$, sendo apenas $3.297,95 \mathrm{~m}^{2}$ de área construída e como já mencionado, está organizada em blocos: o bloco administrativo, onde anexo também estão o bloco dos serviços e a residência das irmãs; os seis blocos de apartamentos: o bloco Santa Catarina, bloco Sagrado Coração de Jesus, bloco Santo Antônio, bloco Santa Inês, bloco N. Sr. De Lourdes, e o bloco Savina; o bloco da piscina, a capela, o salão de eventos e o bloco da lavanderia. Todos são ligados por passarelas cobertas por um telhado de duas águas em telha canal.

Devido a sua composição ser em blocos, a partir do acesso pelo estacionamento, tem-se o bloco administrativo onde estão localizadas as salas dos setores responsáveis pela gestão da instituição, como a sala da diretoria, dos recursos humanos e a secretaria. Também está localizada a sala da assistente social, responsável por intermediar a relação entre os visitantes e os idosos e seus familiares. 


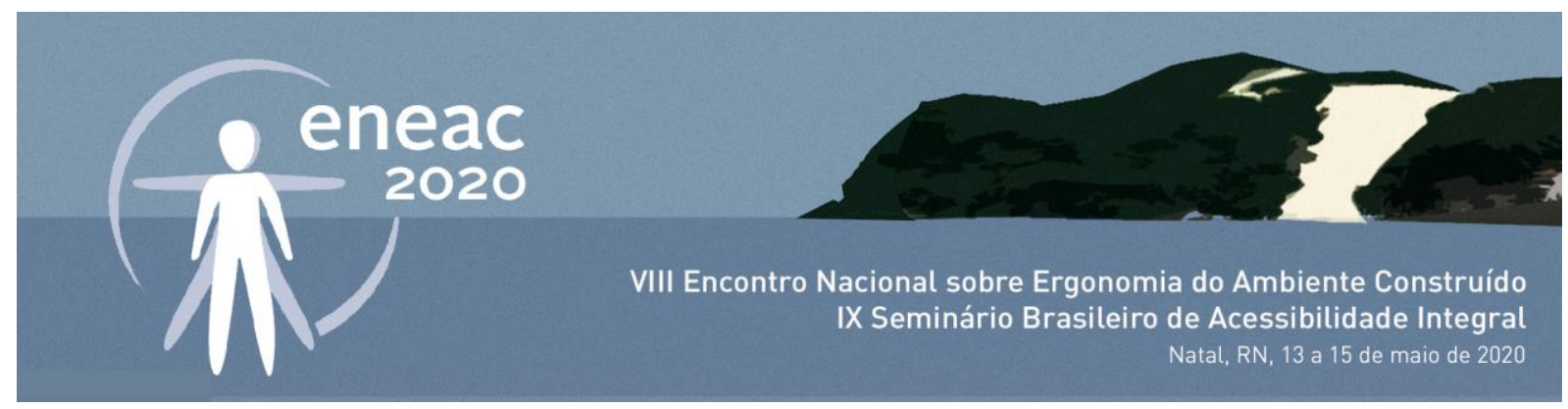

O fluxo de funcionários é maior dentro dos blocos e nas áreas de serviço, como a cozinha. Os funcionários possuem uniforme padronizado com o nome da instituição, sendo o dos funcionários do serviço e que trabalham na cozinha, específicos para suas funções. A cozinha está localizada próximo ao bloco administrativo e da residência das irmãs, onde são preparadas todas as refeições e distribuídas nos blocos. Cada bloco possui um refeitório e uma copa equipada com os itens de uma cozinha, para a necessidade de reaquecimento de algum alimento.

Os blocos dos dormitórios possuem salas de estar e de TV, refeitório e copa, posto médico, rouparia e lavanderia, além do pátio interno. Apenas um dos blocos está adequado às exigências da norma de acessibilidade, NBR 9050/2015, o bloco Nossa Senhora de Lourdes, recentemente reformado para se adequar a mesma. Os demais blocos atendem parcialmente as exigências da norma e estão aguardando recursos para que também sejam reformados. Além disso, embora todos os blocos sejam térreos, a implantação dos mesmos possui alguns desníveis, que são vencidos com rampas (figura 2 e 3).

Figura 2 e 3: As conexões entre os blocos são feitas por passarelas e quando necessário, foram instaladas rampas para vencer os desníveis.
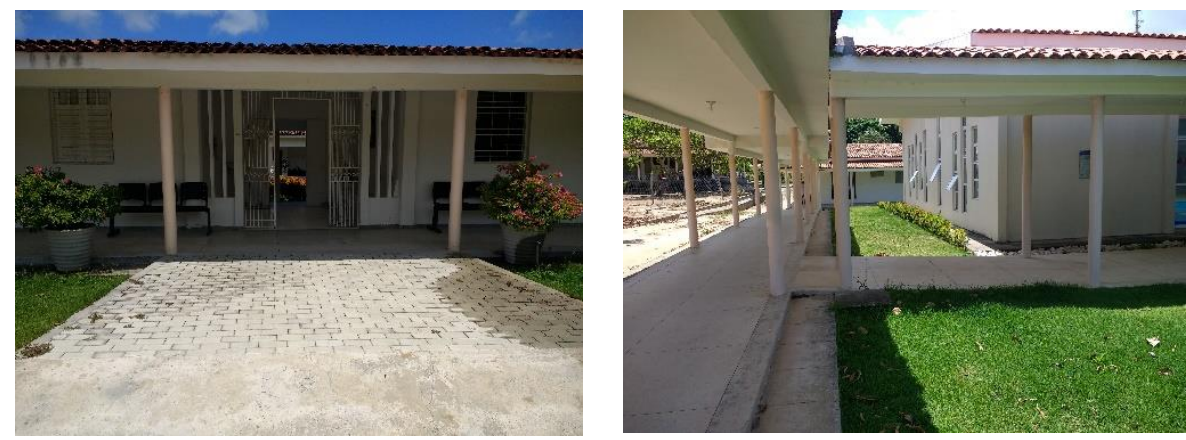

Fonte: Acervo pessoal dos autores, 2017.

\section{ANÁLISE GLOBAL DO AMBIENTE}

Devido às dimensões do conjunto, foi escolhido um dos blocos para realizar a analise utilizando a metodologia ergonômica do ambiente construído, o bloco Santo Antônio, por ser um dos que mais possui residentes. Cada quarto acolhe até três idosos, do mesmo sexo. As atividades nesse bloco podem ser agrupadas em quatro categorias (figura 4):

Setor íntimo: os quartos dos residentes e as áreas de repousos dos funcionários, que alternam entre turnos de 8 horas por dia e prestam cuidados 24 horas por dia aos idosos. A instituição conta com a assistência de 112 profissionais e possui parceria com a universidade Uninassau e Unipê que levam estudantes de fisioterapia para atender os idosos.

Setor social: as áreas livres para acesso dos visitantes e familiares, bem como áreas de "estar" e convívio dos residentes. Neste caso específico, está concentrado no hall de entrada e na circulação que liga os dois lados do bloco.

Setor médico: onde estão localizados os pontos de apoio aos cuidados com a saúde dos idosos, como a sala de enfermagem, o posto médico e o gabinete dentário. 


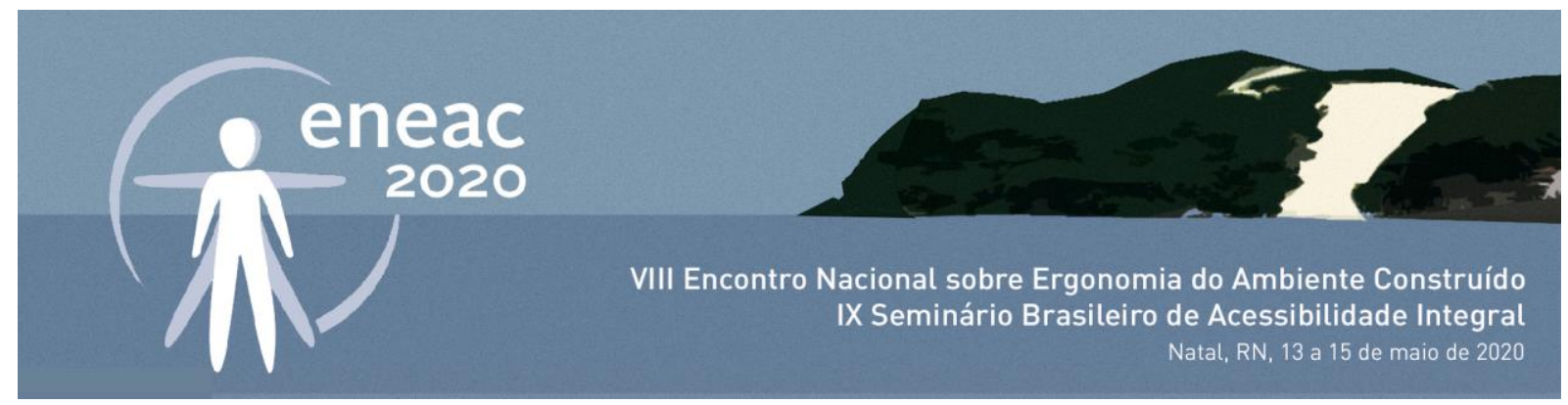

Setor de serviços: onde estão localizadas as áreas molhadas e ambientes de apoio às atividades principais, de limpeza e manutenção.

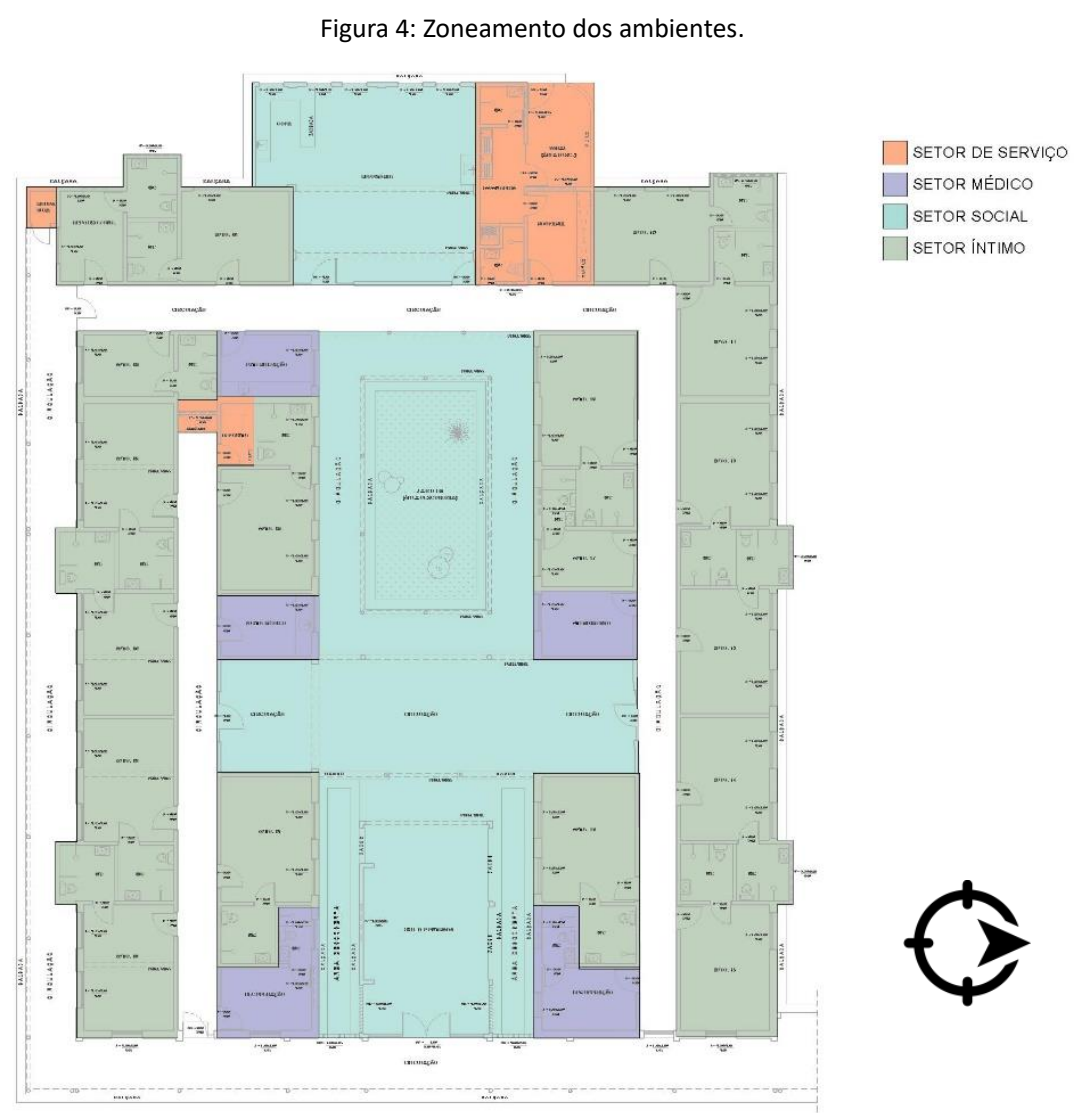

Fonte: Acervo pessoal dos autores, 2017.

Foram realizadas medições em todos os quartos e todos atendem as medidas mínimas de $5,50 \mathrm{~m}^{2}$ de área por cama, incluindo área para guarda roupa e pertences, de acordo com a RDC 283/2005 da Anvisa e de $8,00 \mathrm{~m}^{2}$, de acordo com o Código de Obras de João Pessoa. Além disso, o número de idosos por quarto também está de acordo com o prescrito nas normas.

\subsection{Identificação da configuração ambiental}

Durante essa fase, foi possível adquirir as primeiras características mais concretas sobre o ambiente. A partir de visitas de campo, identificaram-se os condicionantes físico-ambientais da ILPI a fim de entender como se dão as atividades realizadas em um espaço real, dimensionado. Além disso, observaram-se condições de segurança, acessibilidade, conforto ambiental e disposição do mobiliário dos quartos, posto médico e o estar onde os idosos geralmente gostam de ficar.

\subsubsection{Acessibilidade}

Primariamente, foi avaliado o espaço com relação às condições de acessibilidade oferecidas ao cadeirante, de acordo com as definições da Norma Brasileira (NBR) 9050/2015, que "estabelece critérios e parâmetros técnicos a serem observados quanto ao projeto, construção, instalação e 


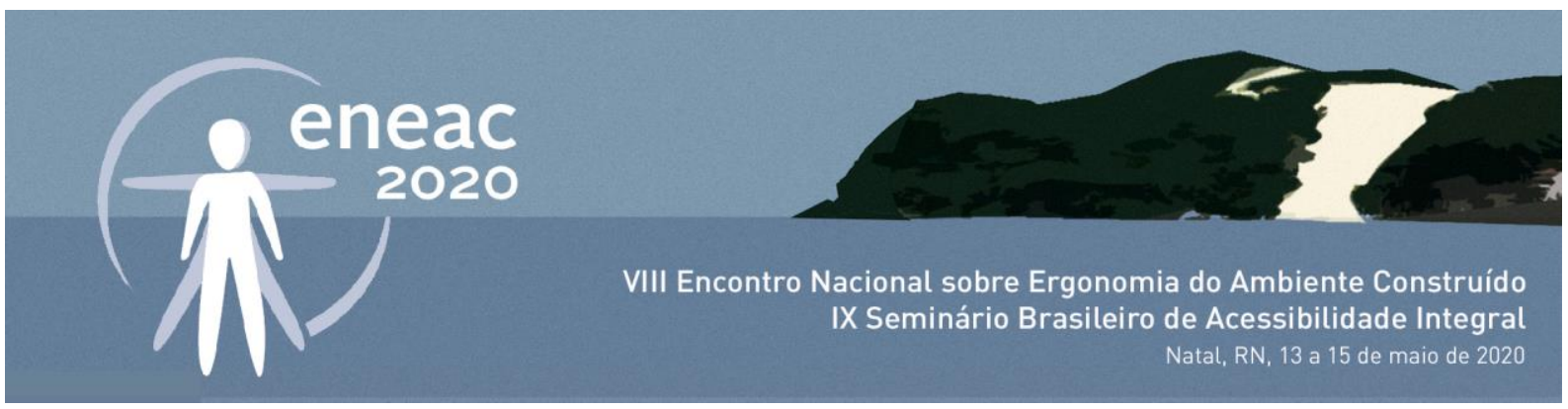

adaptação do meio urbano e rural, e de edificações às condições de acessibilidade" (ABNT, 2015, $\mathrm{p}: 1)$.

Inicialmente, nota-se que as pessoas com deficiência não encontram muitas dificuldades para circular dentro da edificação, mas sim para chegar até lá, pois os blocos são ligados por passarelas cobertas, com diversas rampas, mas sem corrimão ou piso tátil. As circulações, possuem em média $1.50 \mathrm{~m}$ de vão, no mínimo, com corrimão em pelo menos um dos lados. Entretanto, nem todos os trechos possuem corrimão e nenhuma parte do bloco possui piso tátil, conforme visto na figura 5 e 6 . As esquadrias são, em geral, metálicas e em madeira e com sistema de abertura de correr.

Figura 5 e 6: Circulações internas.
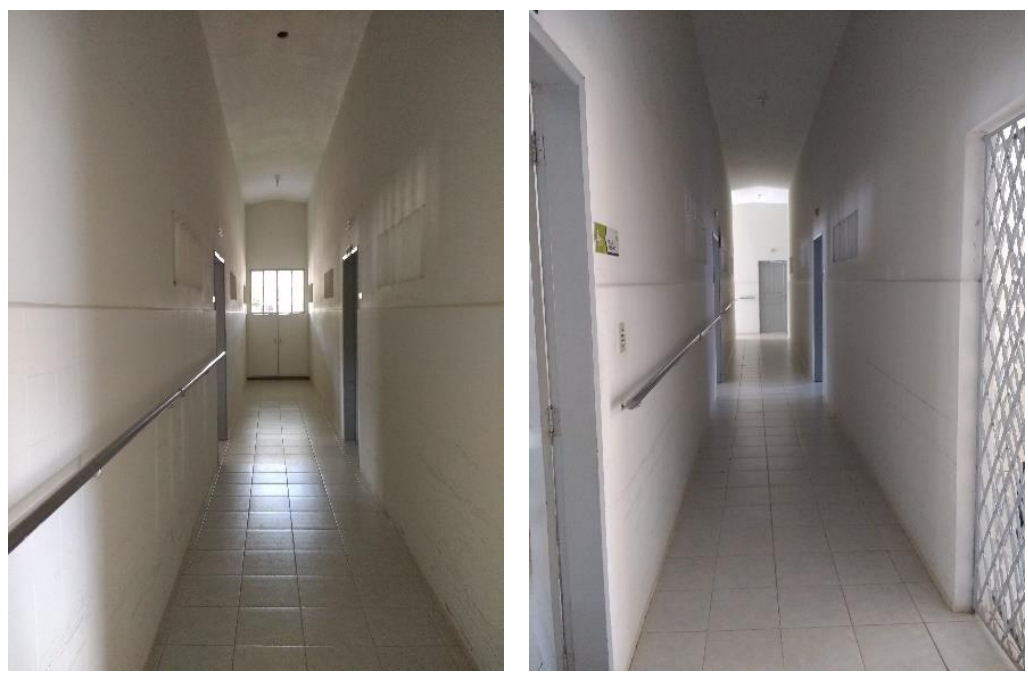

Fonte: Acervo pessoal dos autores, 2017.

Pode-se perceber que a maioria dos ambientes possuem vãos mínimos de $0.80 \mathrm{~m}$, com portas de giro, com maçaneta tipo alavanca, excetuando a porta do banheiro ao lado do refeitório $(0,60 \mathrm{~m} \times 2,10 \mathrm{~m})$, analisando a imagem abaixo (figura 7). Dessa maneira, é válido ressaltar que estes blocos, com suas circulações e portas, estão acessíveis de acordo com a NBR 9050/2005, permitindo, assim o fluxo de pessoas em cadeiras de rodas (P.C.R.), quanto do próprio fluxo de acesso dos ambientes.

Figura 7: Níveis de acessibilidade dos ambientes.
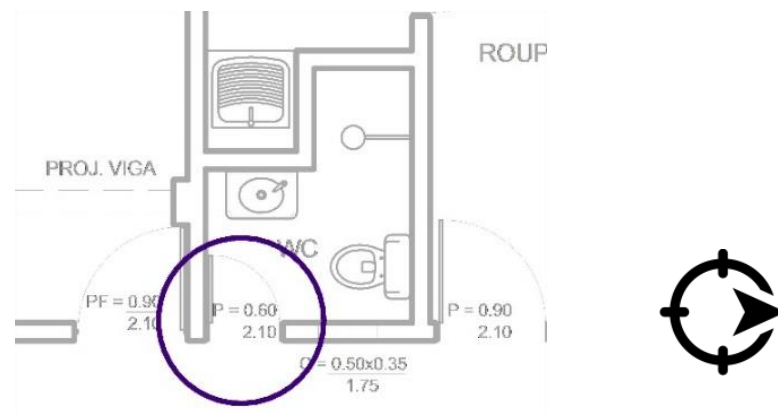

Fonte: Acervo pessoal dos autores (2017). 


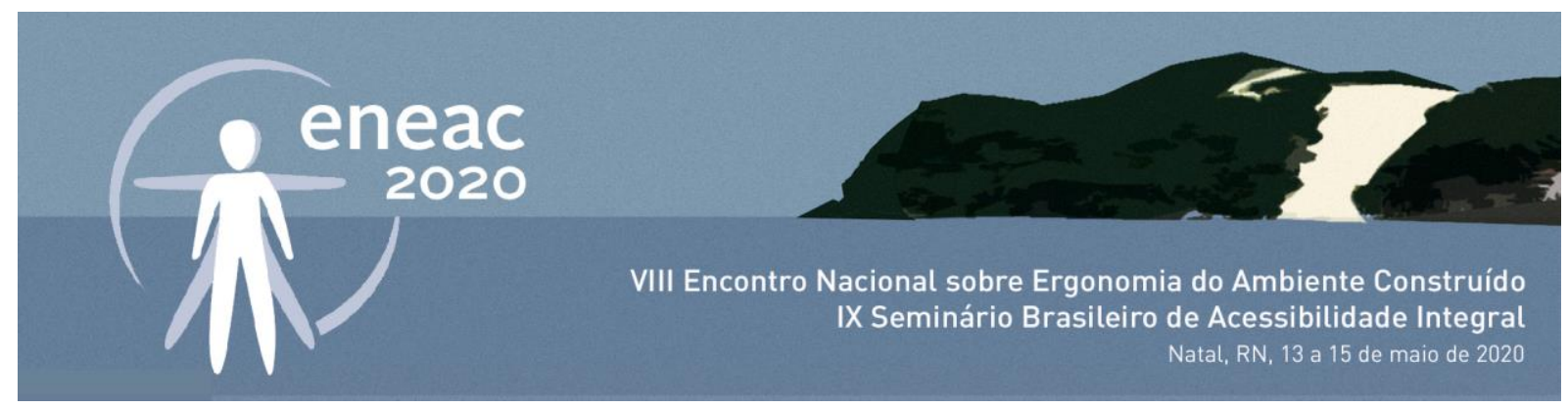

\subsubsection{Segurança e manutenção}

As grandes dimensões não são um empecilho para a constante manutenção e limpeza dos ambientes, que estão sempre limpos e organizados, não sendo percebido nenhum mau cheiro, comum em instituições de longa permanência. Entretanto, por conta da divisão em blocos, os idosos passam a maior parte do dia recolhidos nos halls de entrada, que funciona como um terraço ou na área de estar do bloco, ou dentro dos seus quartos.

Os cuidadores trabalham 24 horas por dia, em sistema de rodizio, com carga horária de 8 horas diárias. Todos trabalham uniformizados, com fardamento com logo da instituição. $\mathrm{O}$ serviço de limpeza é executado três vezes ao dia e os funcionários do serviço gerais são divididos por blocos. A supervisão dos blocos cabe às irmãs, que, embora estejam consideradas dentro do quadro de funcionários, não possuem vínculo empregatício ou recebem salário por isso.

Existe uma preocupação com a segurança dos residentes, sendo todos os blocos constantemente supervisionados não apenas pelos cuidadores, mas pelas irmãs da associação, além da portaria que funciona 24 horas. Como fatores de risco, temos os riscos biológicos, principalmente nas áreas onde são prestados serviços médicos. Outros fatores são a ausência de sinalização ou saída de emergência, o que poderia gerar problemas em caso de incêndio, por exemplo, ou durante algum problema com a rede elétrica que deixasse o bloco sem funcionamento da energia elétrica. Também foi visto que os dormitórios não possuem luz de vigília permanente e campainha de alarme, como exigido pela RDC 283/2005 da Anvisa.

\subsubsection{Layout do mobiliário}

As circulações possuem caminho livre de obstáculos, bem como, nas áreas comuns, o layout do mobiliário não atrapalha o fluxo diário dos idosos e cuidadores, com exceção do posto médico, cujo layout não possibilita a livre circulação por qualquer usuário (figura 8).

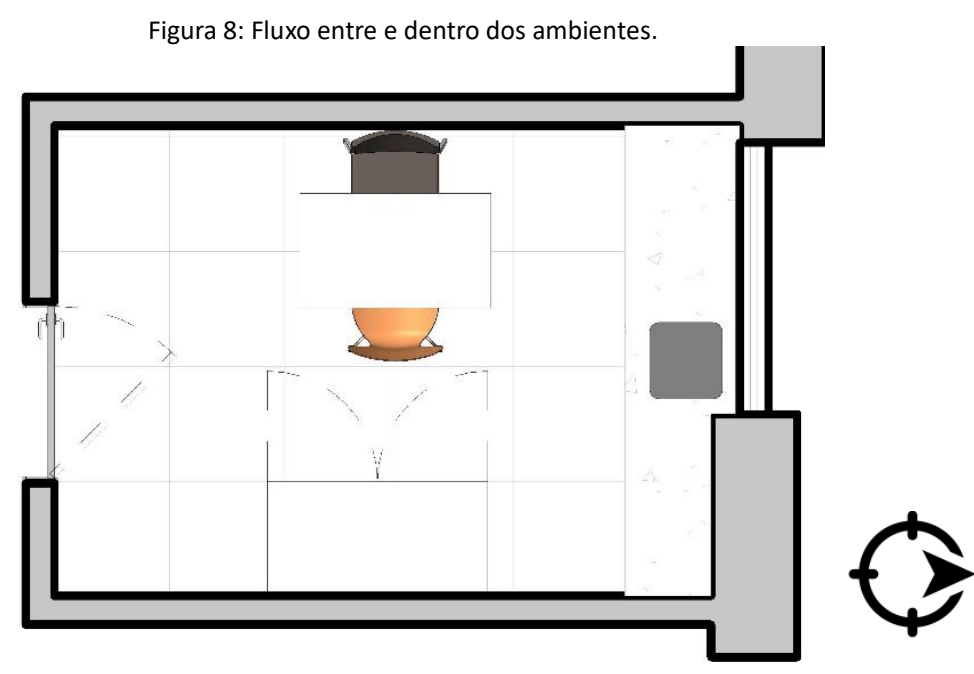

Fonte: Acervo pessoal dos autores (2017).

O mobiliário da copa e refeitório atende às necessidades dos funcionários da instituição, dispondo de uma pia e armários que estão em alturas que não dificultam o seu uso. Já as áreas de estar e terraços 


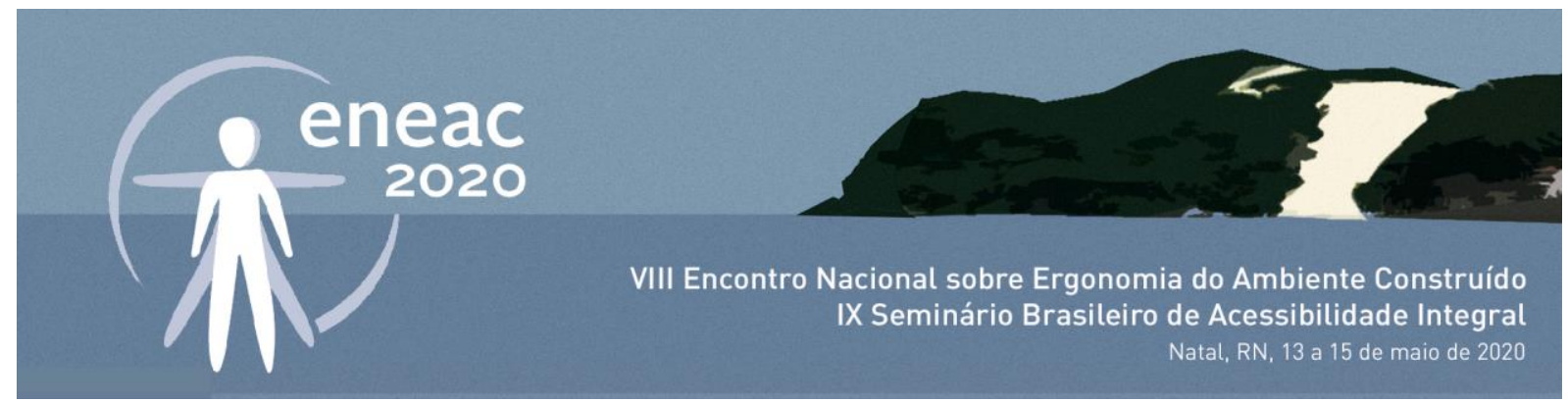

privilegiam o conforto dos usuários deixando espaços entre o seu mobiliário, facilitando a circulação e evitando a sensação de clausura (figura 9).

Figura 9: Os idosos utilizam o hall de entrada como um terraço e uma área de estar.

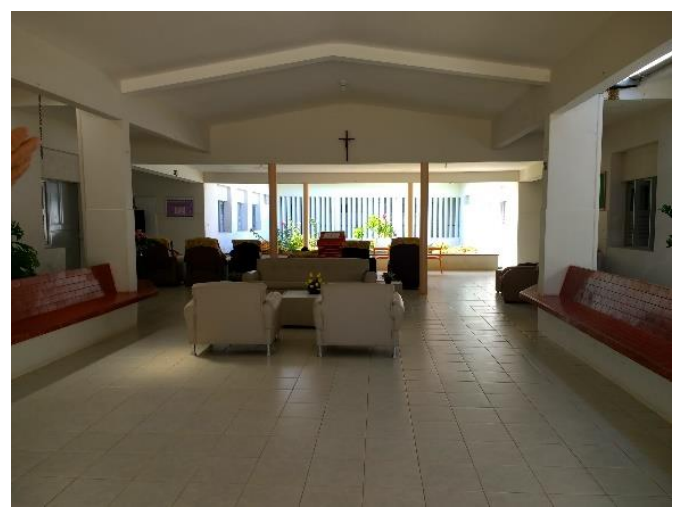

Fonte: Acervo pessoal dos autores, 2017.

No geral, todos os dormitórios são amplos, com mobiliário individual e ocupado por no mínimo dois ou três idosos, possuem aberturas para ventilação de conforto e higienização (figura 10 e 11). Possuem banheiro internamente, os quais, muitos já adaptados com barras de apoio e abertura para fora. Entretanto, nem todos os mobiliários possuem possibilidade de regular as alturas para se adequar melhor ao usuário, causando desconforto. Além disso, qualquer mobiliário com baixa altura oferece dificuldade ao idoso, pois o ato de abaixar-se e bastante difícil para alguns. Observa-se que no projeto, buscou-se voltar os quartos para os pátios internos ou áreas ajardinadas existentes entre os blocos, garantindo sempre uma bela vista e uma amenização das temperaturas pela vegetação.

Figura 10 e 11: Layout e mobiliário de dois dormitórios do Bloco Santo Antônio.
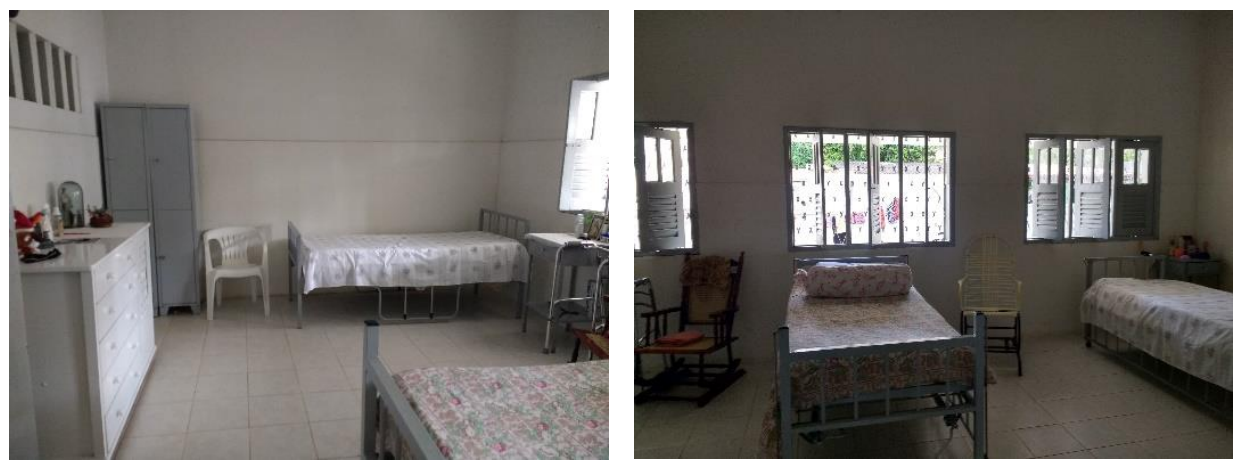

Fonte: Acervo pessoal dos autores, 2017.

\subsubsection{Conforto ambiental}

A instituição possui orientação Leste-Oeste, sendo a maioria dos blocos localizados na orientação norte (blocos dos dormitórios) e sul (bloco administrativo, dos serviços e residências das irmãs) e todos térreos. As edificações do conjunto foram construídas em alvenaria de tijolo cerâmico e cobertas em telha canal sobre laje de concreto e quase nenhum dos ambientes possui forro. As 


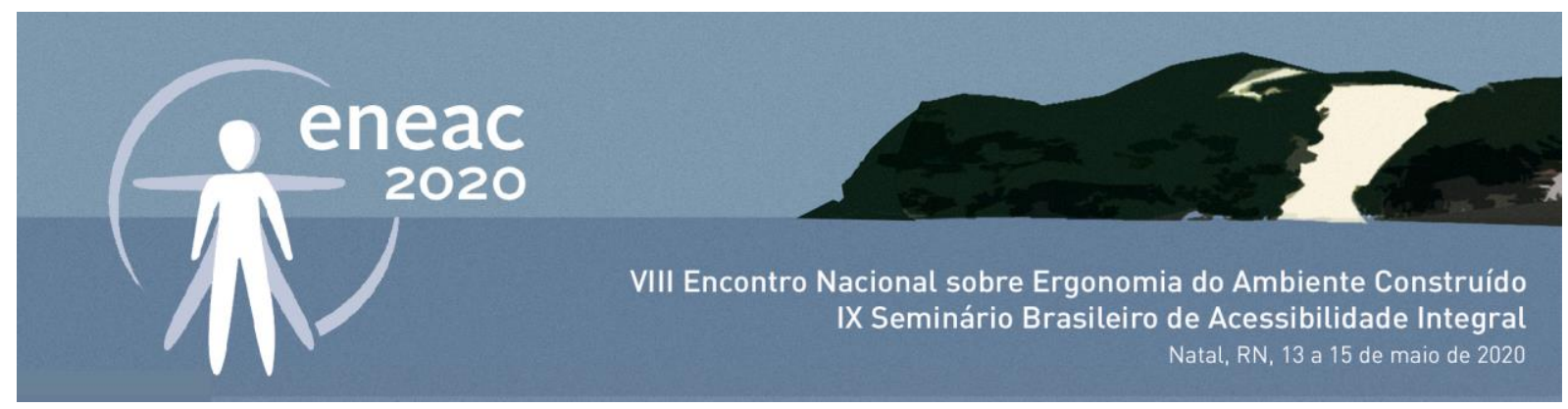

paredes no geral são revestidas com tinta acrílica branca e algumas com revestimento cerâmico, como as circulações internas de todos os blocos, banheiros, copa, lavanderia, copas, postos médicos e refeitórios. O revestimento do piso varia dentro dos blocos, em alguns trechos das passarelas, no salão de festas, sendo predominante o granilite e o revestimento cerâmico na cor branca.

O pé direito dos ambientes é relativamente alto o que ajuda na ventilação e aeração, e juntamente com os pátios internos, cria ambientes amplos e bem ventilados, mas sem perder a escala humana, uma vez que os terraços são as principais áreas de estar dos idosos. É importante ressaltar o baixo nível de ruído percebido dentro de todas as áreas. Mesmo em uma área de intenso fluxo de veículos, a grande maioria dos funcionários e moradores alega que o ambiente é bastante silencioso o dia inteiro, o que é associado por muitos com a sensação de tranquilidade. Além disso, a lavanderia, que possui um nível alto de ruído, está localizada nos fundos do conjunto, bastante isolada dos demais blocos, sendo percebido o ruído apenas quando se aproxima da mesma.

Com relação à arborização externa, que favorece o conforto ambiental, existem diversas áreas com vegetação de médio e grande porte, principalmente entre os blocos e nos fundos da edificação. A maior parte do solo não é impermeabilizada, é em terra batida ou em jardins isolados, e as áreas impermeabilizadas correspondem às passarelas que ligam os blocos e ao estacionamento. Devido à grande dimensão do terreno, a vegetação, embora de copa larga e densa, muitas vezes não é utilizada como forma de amenização climática por meio do sombreamento sendo espalhadas pelo terreno muitas vezes de forma isolada. A área mais ajardinada é ao redor da capela existente dentro do conjunto. Com relação ao bloco Santo Antônio, foram realizadas medições térmicas, lumínicas e acústicas, a fim de comprovar as informações levantadas nas visitas à instituição como um todo e apresentadas acima.

Devido à sua implantação, este bloco, que possui um tipo de planta espelhada, apresenta um lado que recebe a insolação solar direta nos horários mais quentes e por isso, esses ambientes apresentaram maiores temperatura no dia em que as medições foram realizadas no período da tarde (poente), sendo a temperatura mais alta registrada a de $30.5^{\circ} \mathrm{C}$ e a menor de $29.3^{\circ} \mathrm{C}$. Os dormitórios localizados nessa posição estão sempre vazios durante o dia, pois os idosos, a fim de evitarem o desconforto do calor intenso e da falta de ventilação, ocupam o terraço e áreas de estar. Salientando que os ventos em João Pessoa predominam na direção leste, foi comprovado a partir das medições térmicas que mesmo os ambientes com aberturas voltadas para o leste, os ventos atingem valores precários de velocidade, uma vez que a própria implantação dos blocos cria barreiras para a passagem do vento pelo interior da edificação, que possui abertura que favorecem a ventilação cruzada.

No tocante ao conforto lumínico, de acordo com a NBR 5413/1992 - ainda que ela tenha sido revogada, foi considerada a norma que mais se adequava com local estudado para a pesquisa, uma vez que a NBR ISO/CIE 8995-1 e a NHO 11 tratam-se, especificamente, de locais de trabalho determina que para iluminação geral em áreas residências, para ambientes de estar ou geral em quartos de dormir os valores iluminância devem ser de 100 a 200 lux, estando os dormitórios e terraços/área de estar adequados. No entanto, com relação aos níveis de lux para locais de leitura, escrita, bordado, ou a iluminação local nos dormitórios (cama, espelho, penteadeira) foram encontrados níveis de iluminação muito discrepantes (mesmo em pontos próximos entre si), como valores como 121 lux na mesa localizada no posto médico e de 146 lux, em uma das mesas de cabeceira de um dos dormitórios, valores esses bem abaixo do recomendado pela norma, que pede 


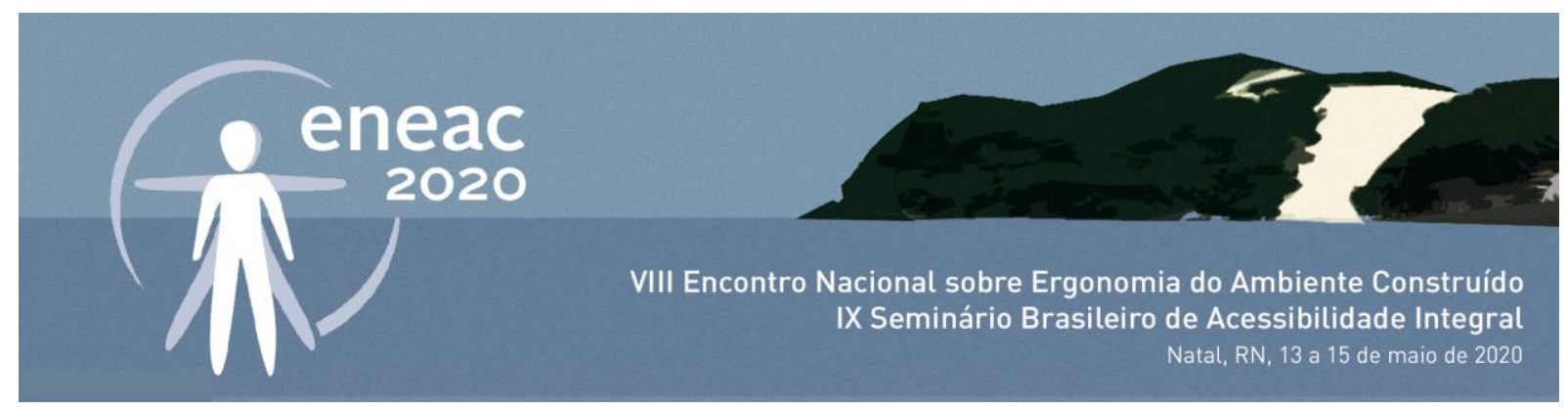

entre 200 a 500 lux. Sendo assim, para destes problemas a resolução, ficou claro que seriam necessários cálculos para a quantidade de luminárias, bem como um estudo da disposição dessas luminárias e ainda uma preocupação com o tipo de lâmpada e luminária adequadas em cada um dos setores. Um ponto positivo são as inúmeras e grandes aberturas, que permitem a passagem de luz natural durante o dia, o que reduz custos com energia.

Nas medições em cada ambiente do bloco para a determinação do conforto acústico dos usuários, nos quais os níveis foram comparados com as definições da NBR 10152, notou-se que em áreas de circulação e estar, são aceitáveis valores entre 40 a 50 decibéis, estando a média nesses lugares um pouco acima do recomendado, chegando a 59.6 decibéis em alguns momentos. Já os dormitórios, onde são aceitáveis valores entre 35 a 45 decibéis, também estão com médias um pouco acima da norma, chegando a 52.8 decibéis.

Além disso, através de conversas com o gerente da Rádio e com depoimentos de funcionários percebeu que eles sentiam a necessidade da criação de outros espaços e relocação dos existentes. Um exemplo disso era o jornalismo em que seria interessante sua aproximação com o estúdio principal para garantir uma boa e mais direta comunicação entre as atividades realizadas nas mesmas. É vigente também, a criação de uma recepção que garantiria a presença de um ambiente intermediário (de espera), para diminuir zonas conflitantes no corredor.

\subsection{Análise do ambiente em uso}

Propondo um estudo sobre as condições de vivência na instituição, fomos a campo com a finalidade de obter maiores informações sobre o arranjo físico da mesma e observar como se dá o dia - a - dia no local. Esse estudo foi de fundamental importância, pois assim pudemos ver se os padrões de espaço obedecem às necessidades e conforto dos que o usam. É notória a satisfação por parte dos idosos e dos funcionários no trabalho, pois o ambiente é bastante dinâmico para os funcionários e ao mesmo tempo, calmo e tranquilo para os residentes.

De maneira geral, ao se chegar à ILPI, os visitantes são convidados a se dirigirem à mesa da recepcionista. Durante esse percurso, temos poltronas e bancos que tratam de acolhê-los. Quando os mesmos necessitam ter acesso a algum dos blocos, ele é feito em sua grande maioria, de forma indireta, pelas passarelas, sendo de fácil acesso, entretanto com distâncias um pouco grandes.

Como atividades de lazer, os idosos recebem visitas de voluntários, que buscam propiciar atividades para diminuir a ociosidade e estimular a socialização. Infelizmente, conforme informado pela assistência social da instituição, aproximadamente quinze idosos da totalidade recebem visitas constantes dos seus familiares, a maioria só recebe visitas em datas comemorativas e reuniões, o que é muito ruim para esses idosos, que se sentem muitas vezes abandonados. Por isso, uma das missões da instituição é o acolhimento não apenas como moradia, mas também como um local de atenção, carinho e afeto.

\subsubsection{Análise da percepção do usuário}

Nessa etapa, buscamos colocar o usuário em primeiro plano e finalmente entender os efeitos psicológicos que o ambiente de estudo proporciona aos mesmos, sendo os idosos a principais usuários considerados no estudo. Com isso, nos valemos de um questionário contendo perguntas como: 


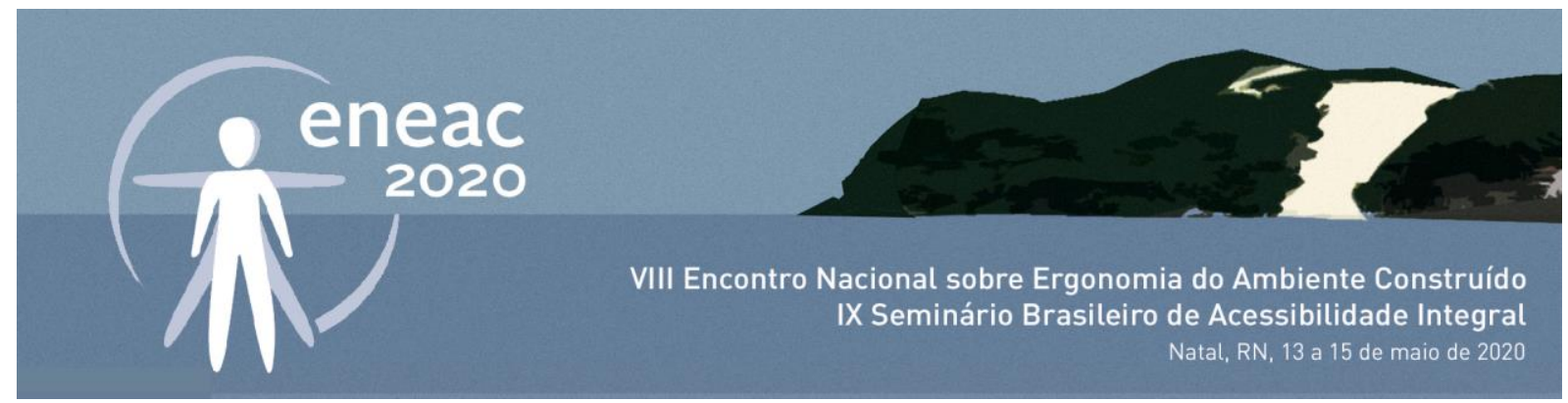

- Qual o seu local preferido na instituição?

- O que mais gosta na instituição?

- Em seu dormitório existe mobiliário pessoal da residência anterior?

Após aplicação dos questionários e formulários tem-se que a maioria dos idosos sente-se feliz com o ambiente em que vivem, entretanto $20 \%$ dos idosos sentem falta de mais atividades ao longo do dia, sentindo-se muitas vezes ociosos, pois a maior parte passa os dias no quarto ou nas salas de convívio, e 70\% gostariam de mais áreas ajardinadas e 30\% de quartos individuais para ter mais privacidade. Os pontos mais críticos são relacionados à temperatura e ventilação, pois, $62 \%$ dos idosos relataram que os quartos são quentes e abafados e com relação à articulação entre os espaços, pois $69 \%$ sentem dificuldades ao caminhar para acessar algumas áreas da instituição.

Abaixo temos dois dos demais gráficos (gráficos 1 e 2) criados para analisar os dados gerados pelos questionários, sendo esses sobre o nível de satisfação dos idosos com relação ao tamanho (dimensionamento) e disposição dos móveis (layout) dos dormitórios.

Gráfico 1 e 2: Nível de satisfação dos idosos com o dimensionamento (1) e layout dos dormitórios (2).
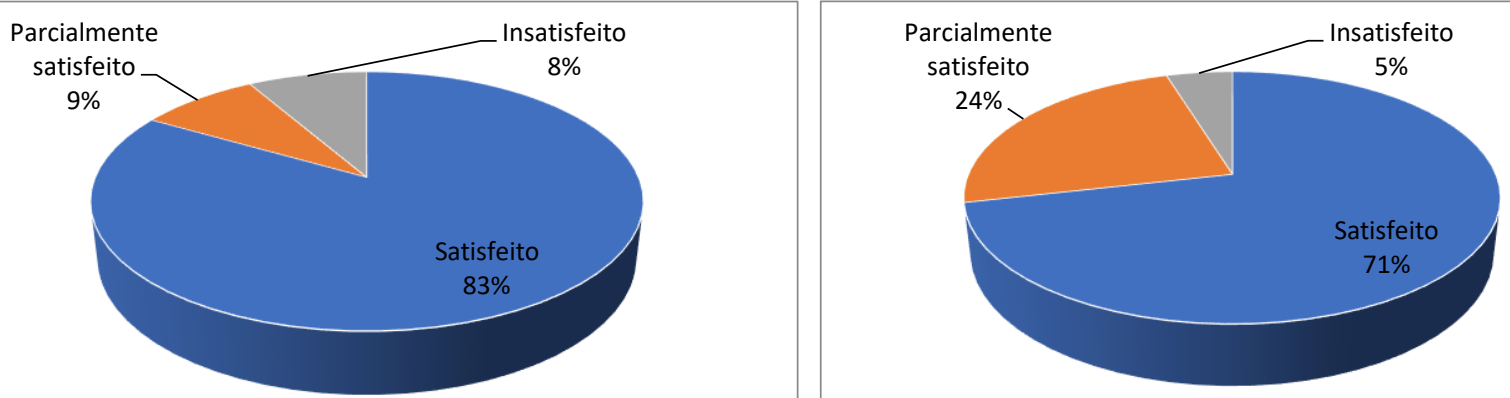

(1)

Fonte: Os autores, 2020.

\section{DIAGNÓSTICO ERGONÔMICO}

A pesquisa desenvolvida ao longo do presente trabalho, assim como a experiência vivida na ILPI intitulada Lar de Providência, proporcionou algumas observações positivas e negativas sobre o mesmo, principalmente no nosso local de estudo, o bloco Santo Antônio. Percebeu-se que o ambiente é acessivelmente bom para os idosos moradores dessa instituição, necessitando apenas de alguns ajustes, como a instalação de corrimão nas áreas que não possuem, já que muitos, possuem mobilidade reduzida ou são pessoas com cadeira de rodas (P.C.R). Entretanto, como não só podemos avaliar a acessibilidade, foi na análise do conforto ambiental que encontramos os maiores pontos negativos e que são criticados pelos usuários do local.

Após as medições de conforto, foram apontados problemas referentes à iluminação artificial, mais precisamente nos locais de atividades que necessitam de luz focal, como a leitura, escrita e bordado. Para que esse problema seja resolvido, é necessário um estudo para uma melhor disposição e quantidade de luminárias, além de cálculos para atingir a luminância correta de acordo com a NBR $5413 / 1992$. 


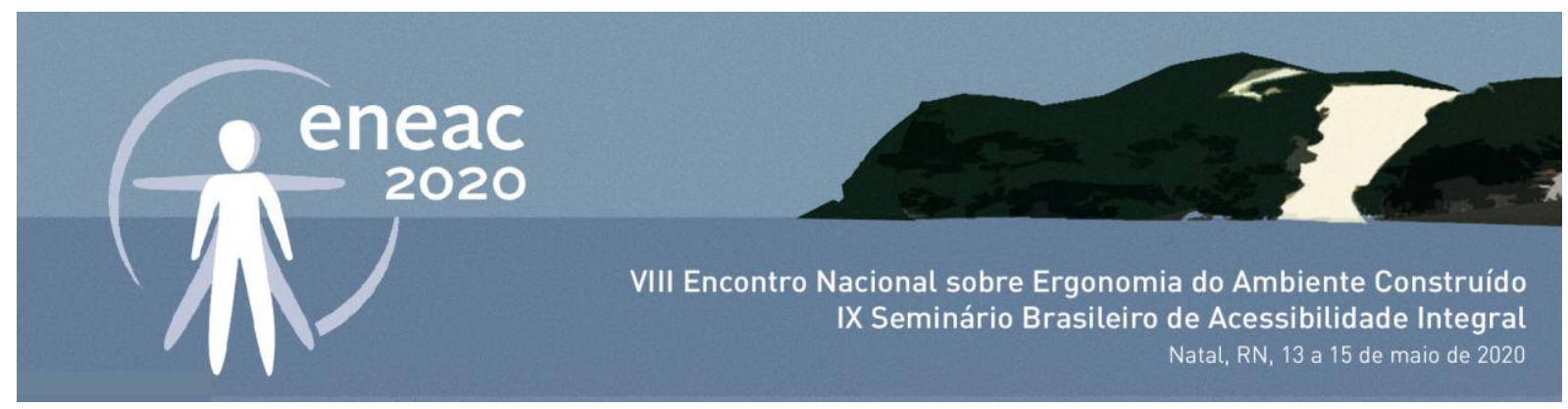

Outro desconforto encontrado após medições, e retificado através da análise de percepção dos usuários, foi a falta de ventilação e altas temperaturas nos dormitórios - principalmente os voltados para o lado oeste - sendo o lado poente e consequentemente o que possui temperaturas mais elevadas durante a tarde. Uma boa solução seria a colocação de brises nas fachadas, afim de evitar o sol direto, além da instalação de mais ventiladores, já que, a disposição dos blocos não terá como ser feita (fator que também influencia na circulação dos ventos).

Por fim, através da análise de percepção dos usuários e conversas informais com os idosos, foi percebido que eles sentem a necessidade da criação de outros espaços ajardinados de lazer e mais atividades de lazer. Essas questões poderiam ser resolvidas com estudos de um novo layout para o jardim descoberto, usando mais vegetação e mobiliários que gerassem mais comunicação e atividades entre eles.

\section{CONSIDERAÇÕES FINAIS}

A preocupação do trabalho desenvolvido foi, então, verificar a interferência dos espaços físicos na rotina dos idosos moradores de uma ILPI e identificar as condições de ergonomia e conforto desses ambientes e como eles poderiam impactar positivamente numa melhor estadia dessa população. Assim, esses atributos elevando a qualidade, adequação e agradabilidade dos espaços estudados, aplicáveis aos ambientes voltados para a terceira idade, mostraram-se tão importantes quanto o atendimento dado pela equipe médica e demais funcionários.

Viu-se, também, que não é impossível se atingir um ponto de sensação ideal de conforto sensorial, principalmente térmico, visual, tátil e auditivo. Dessa maneira, a análise realizada através do diagnóstico in loco, foi de fundamental importância, pois com ela foi possível detectar a influência dos fatores espaciais, ambientais e organizacionais, que influenciam de forma direta no desenvolvimento das atividades e no bem-estar das pessoas que moram, trabalham e visitam o Lar da Providência.

\section{REFERÊNCIAS}

Associação Brasileira de Normas Técnicas. ABNT. NBR 9050/2015- Acessibilidade a edificações, mobiliário, espaços e equipamentos urbanos. Norma Brasileira - Associação Brasileira de Normas e Técnicas - ABNT, 2015.

Associação Brasileira de Normas Técnicas. ABNT. NBR 10152/1987 - Níveis de Ruído para conforto acústico. Norma Brasileira - Associação Brasileira de Normas e Técnicas - ABNT, 1987.

Associação Brasileira de Normas Técnicas. ABNT. NBR 5413/1992 - lluminância de interiores. Norma Brasileira - Associação Brasileira de Normas e Técnicas - ABNT, 1992.

ANVISA. RDC no 283 de $\mathbf{2 6}$ de setembro de 2005. Resolução da Diretoria Colegiada. Aprova o Regulamento Técnico que define normas de funcionamento para as Instituições de Longa Permanência para Idosos. Brasília, 2005. <Disponível em: http://portal2.saude.gov.br/saudelegis/leg_norma_pesq_consulta.cfm.>. Acesso em setembro de 2017.

BRASIL. Lei no 10.741 de 19 de outubro de 2003. Estatuto do Idoso.

BRASIL. Lei no 8.842 de 4 de janeiro de 1994. Política Nacional do Idoso.

BRASIL. Emenda Constitucional no 53 de 19 de dezembro de 2006. Constituição Federal.

FRANK, Eduardo. Terceira Idade, Arquitetura e Sociedade. Porto Alegre: Editora 4+, 2016.

JOÃO PESSOA. Lei no 1.347 de 27 de abril de 1971. Institui o Código de Obras do município de João Pessoa e dá outras providências. 


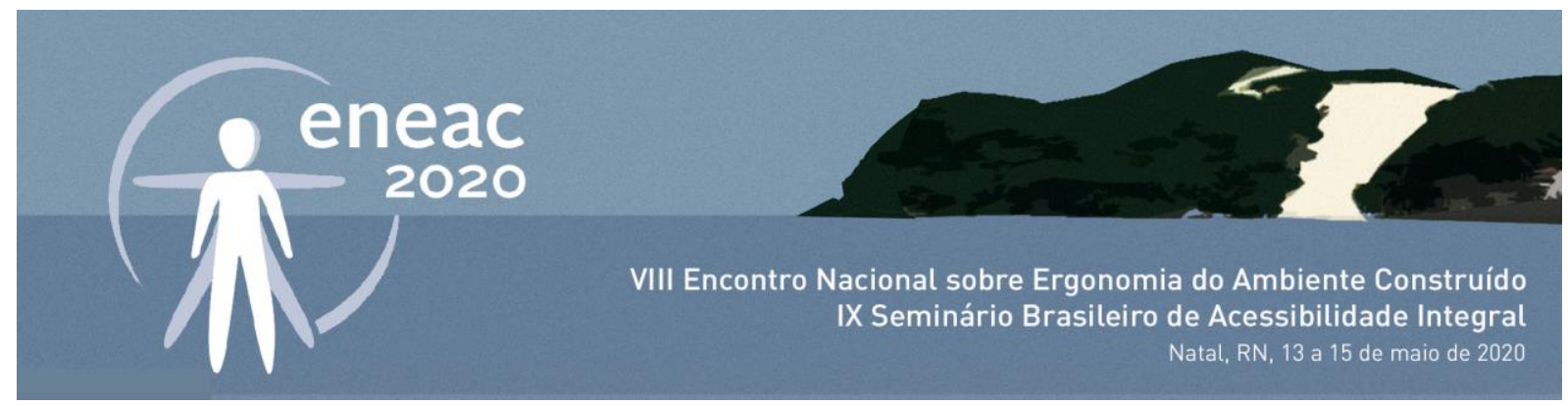

RINCO, Michelle; LOPES, Andrea; DOMINGUES, Marisa Acioly. Envelhecimento e Vulnerabilidade Social: discussão conceitual à luz das políticas públicas e suporte social. Revista Temática Kairós Gerontologia,15(6),

"Vulnerabilidade/Envelhecimento e Velhice: Aspectos Biopsicossociais", pp. 79-95. Online ISSN 2176-901X. Print ISSN 15162567. São Paulo (SP), Brasil: FACHS/NEPE/PEPGG/PUC-SP. Dezembro, 2012.

VILLAROUCO, Vilma, 2002. Avaliação ergonômica do projeto arquitetônico. 12을 Congresso Brasileiro de Ergonomia. Anais... Recife: ABERGO.

VILLAROUCO, Vilma, 2008. Construindo uma Metodologia de Avaliação Ergonômica do Ambiente - AVEA. 14을 Congresso Brasileiro de Ergonomia. Anais...Porto Seguro: ABERGO.

\section{NOTAS}

' Manual de funcionamento da Sociedade Brasileira de Geriatria e Gerontologia. Seção São Paulo (2002-2003).

ii Ana Amélia Camarano é pesquisadora do Ipea e coordenadora de Estudos e Pesquisas de Igualdade de Gênero, Raça e Gerações, da Diretoria de Estudos e Políticas Sociais (Disoc). Camarano é doutora em population studies pela London School of Economics e pós-doutora pela Universidade de Nihon, no Japão. Ela tem como principal linha de pesquisa a demografia, com ênfase em envelhecimento populacional e arranjos familiares. <Dados disponíveis em:

https://www1.folha.uol.com.br/cotidiano/2018/07/total-de-idosos-que-vivem-em-abrigos-publicos-sobe-33-em-cincoanos.shtml>. Acesso em setembro de 2017.

iii A Anvisa refere-se na RDC 283, aos que chama de 'grau de dependência do idoso', que é "condição do indivíduo que requer o auxílio de pessoas ou de equipamentos especiais para realização de atividades da vida diária" (ANVISA, 2005, p: 5). Essa definição da Anvisa diz respeito as atividades de vida diária (AVD) e as atividades instrumentais de vida diária (AIVD) e representam as habilidades que, geralmente, o ser humano precisa ter para viver de forma independente. A definição abrange graus de dependia I, II e III. 